Eur J Health Econom $2005 \cdot[$ Suppl 1] 6:30-36 DOI 10.1007/s10198-005-0316-z

Published online: 4 November 2005

(c) Springer Medizin Verlag 2005
Reinhard Busse · Tom Stargardt · Jonas Schreyögg

Department of Health Care Management, Berlin University of Technology, Berlin, Germany

\section{Determining the "Health Benefit Basket" of the Statutory Health Insurance scheme in Germany}

\author{
Methodologies and criteria
}

\section{Organizational structure and actors involved in the definition of benefit catalogues}

A fundamental aspect of the German health care system is the sharing of decision-making powers between the federal government, the individual states, and designated self-governmental institutions. Responsibilities are traditionally delegated to membership-based, selfregulated institutions of payers and providers that are involved in financing and delivering health care. In the largest scheme (which covers $88 \%$ of the population), the Statutory Health Insurance (SHI), sickness funds, their associations and associations of SHI-affiliated physicians and dentists are recognized as quasipublic corporations. These corporatist bodies constitute the self-regulated structures that operate the financing and delivery of benefits covered by the SHI scheme within the legal framework of the Social Code Book (SGB) V [1].

In joint committees of payers (associations of sickness funds) and providers (associations of physicians and/or dentists and/or the Hospital Federation) legitimized actors define benefits, prices, and standards (federal level) and negotiate horizontal contracts to control and sanction their members (regional level). The verti- cal implementation of decisions taken at senior levels is combined with strong horizontal decision making and contracting among the legitimized actors involved in the various care sectors [2].

Physicians treating SHI-insured patients are organized into 17 regional physicians' associations. The Federal Association of SHI Physicians is responsible for cooperation on the federal level. SHI-accredited dentists are organized the same way as physicians through 17 dentists' associations and the Federal Association of SHI Dentists. The German Hospital Federation is also involved in the decision-making process.

The payers' side is made up of autonomous sickness funds organized on a regional and/or federal basis. They are obliged to raise contributions from their members and to determine the contribution rate necessary to cover expenditures. Their responsibilities include contracting, negotiating prices, quantity and quality assurance measures. Services covered by such contracts are usually accessible to all fund members without any prior approval by the fund, except for preventive spa treatments, rehabilitative services and shortterm home nursing care. If there is any doubt, the sickness funds must obtain an expert opinion on the medical necessity for treatment from the Medical Review
Board, which serves as a joint institution of the sickness funds.

The most important body in the benefit negotiations between sickness funds and physicians concerning the scope of benefits is the Federal Joint Committee. Based on the legislative framework the Committee issues directives relating to all sectors of care. The main body of the Committee consists of nine representatives of the federal associations of sickness funds, nine representatives from provider groups, two neutral members with one proposed by each side, and a neutral chairperson-accepted by both sides. In addition, nine nonvoting representatives of formally accredited patient organizations have the right to participate in consultations, and to propose issues to be assessed and decided upon. The directives of the Committee are legally binding for all actors in the SHI scheme. These directives primarily concern the coverage of benefits and assure that $\mathrm{SHI}$ services are adequate, appropriate, and efficient.

The actual criteria defining benefits vary widely between sectors and types of catalogues. The most important benefit catalogues in the German SHI scheme and its underlying criteria are displayed in $\bullet \mathbf{T a}$ bles 1 and 2. This article concentrates on $\mathrm{HC} 1$ (services of curative care) of the International Classification for Health Accounts (ICHA) taxonomy [3]. 


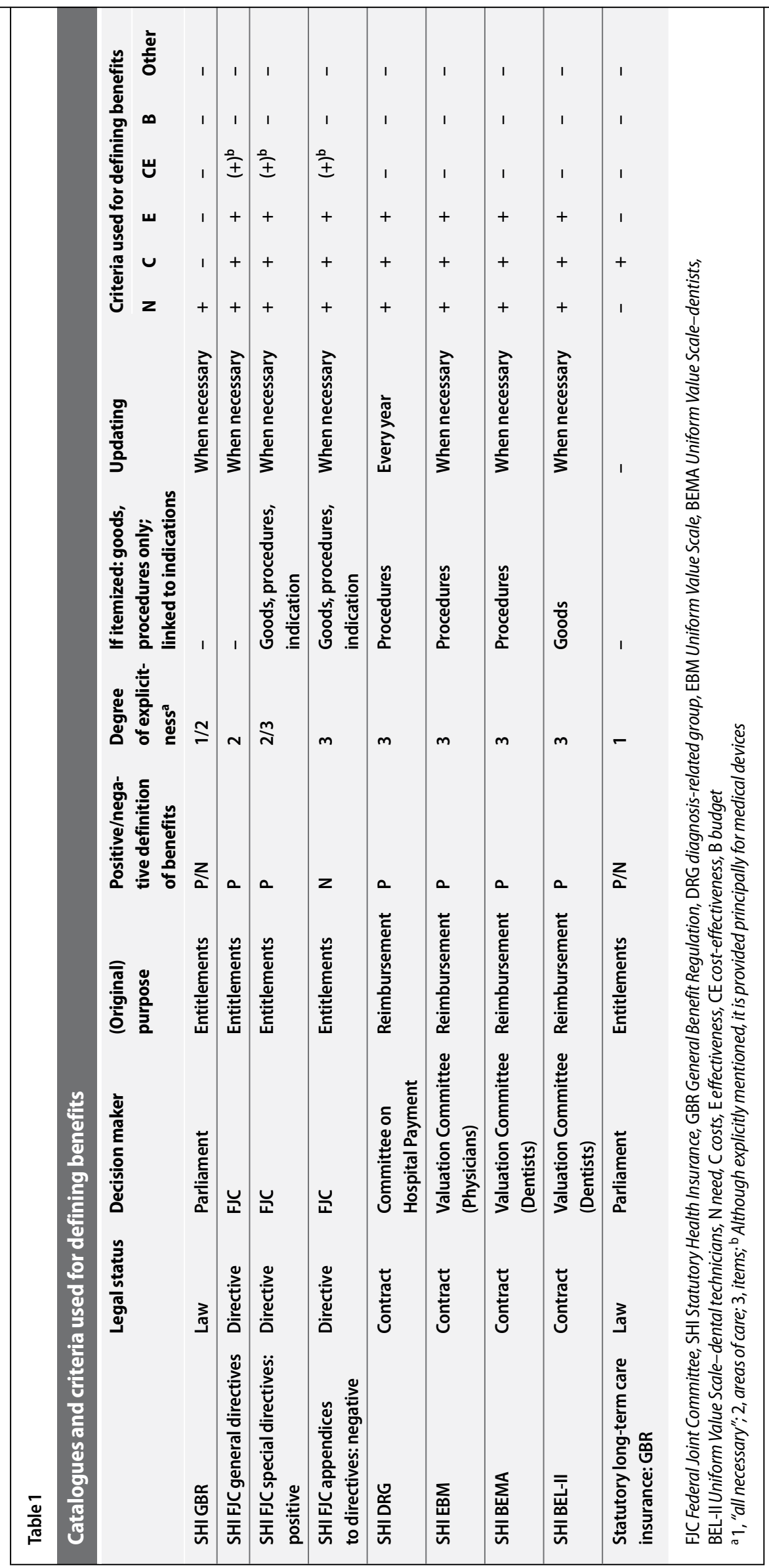

\section{In-patient curative care}

If curative care (i.e., to detect, cure, prevent the worsening, or relieve the discomforts of accompanying diseases) cannot be achieved by ambulatory treatment (SGB V, Sect. 39), the insured party is entitled to inpatient treatment in accordance with SGB V, Sect. 27. This health care entitlement is linked to a copayment of $€ 10$ per calendar day to a maximum of $28 \mathrm{cal}$ endar days per year [SGB V, Sect. 39(4)1].

Hospital services are granted in accordance with the care ability of each hospital and with the level of care assigned to each hospital. In each individual case the provision of services needs to be suitable and adequate for the insured. This includes medical treatment, nursing care, the provision of pharmaceuticals, cures and therapeutic appliances, as well as board and accommodation [4].

Hospital care may be only provided in hospitals included in the hospital plan of the respective federal state, in university hospitals, or in hospitals that have concluded a service provision contract with the sickness funds (SGB V, Sect. 108). While the spectrum of services provided by the respective hospitals is indirectly determined by the hospital plan (which also determines governmental subsidies for investments), the reimbursement for the provided services is decided in negotiations between each hospital and the association of sickness funds.

The Federal Joint Committee presides over matters of exclusion of health care services, and/or the evaluation and examination of treatment methods; the Committee handles these matters in response to requests from the federal associations of sickness funds and the German Hospital Federation. The method under examination will be scrutinized as to its suitability to provide adequate, expedient, and economical care for the insured persons, with general state-of-the-art medical knowledge taken into consideration. Should the examination reveal that the method does not meet the aforementioned, it may no longer be provided at the expense of the SHI system. In such instances, the Federal Joint Committee issues a corresponding directive according to SGB V, Sect. 137c (1) (see $\bullet$ Fig. 1). Health care services in the 
Eur J Health Econom 2005 · [Suppl 1] 6:30-36 DOI 10.1007/s10198-005-0316-z

○) Springer Medizin Verlag 2005

Reinhard Busse · Tom Stargardt Jonas Schreyögg

\section{Determining the "Health Benefit Basket" of the Statutory Health Insurance scheme in Germany. Methodologies and criteria}

\begin{abstract}
The issue of defining health benefit catalogues has recently gained new importance in Germany as a result of the creation of the new Institute for Quality and Efficiency. The Institute was designed to support the Federal Joint Committee conducting effectiveness studies for benefit coverage decisions. The Committee and the contractual partners (sickness funds and providers) define the benefit catalogues for the Statutory Health Insurance in the framework of Social Code Book V, Germany's most relevant health care scheme. Unlike other countries, the German federal government limits its regulatory role to defining procedures that determine the scope of Statutory Health Insurance services. The explicitness of the benefit catalogues varies greatly between different sectors. While benefits in outpatient care are rather explicitly defined, benefit definitions for inpatient care are vague. It is argued that the establishment of the new Institute and the development of the DRG system are initial steps towards a more effective and explicit benefit catalogue.
\end{abstract}

\section{Keywords}

Health benefit plans - Germany . Health services · Health priorities . National health programs framework of clinical studies are not subject to the directive. This means that all health care services that are not excluded by a directive of the Federal Joint Committee may be provided at SHI's expense.

The SHI Reform Act 2000 required the selection and implementation of a case fee system for reimbursement effective as of 1 January 2003. On 27 June 2000 the federal associations of sickness funds, the Association of Private Health Insurance, and the German Hospital Federation adopted the Australian system of diagnosis-related groups (DRGs) as the basis for developing a German DRG system. On 10 May 2001 they founded the Institute for the Payment System in Hospitals (InEK) which is intended to support the introduction and the further development of the DRG system. The InEK is controlled and supervised by the Committee on Hospital Payment, an institution consisting of representatives from the contracting partners (see - Fig. 1). The matters addressed by the DRG Institute consist of defining the DRG case groups, the maintenance of the DRG system, and its severity classification system, the development of a coding directive and proposals for adapting German modifications of the International Classification of Diseases ICD-10 and the Operating Procedures System (OPS) into the DRG system. The Institute is also responsible for the calculation of DRG cost weights and individual adjustments within the DRG system.

As the basis for the new pricing system a uniform case fee catalogue with fixed payments for services and benefits, valid throughout Germany, was developed. The catalogue lists all procedures (services) performed in hospitals in accordance with respective clinical diagnoses. At the same time the DRG system constitutes the catalogue of services and benefits covered by the SHI scheme for inpatient care. The inclusion of new health care services in the DRG system is reflected at the beginning of each year when a new version of the OPS and the ICD-10 is made available and is linked to a DRG [5].

The Case Fees Catalogue of 2005 consists of 876 DRGs, of which 33 are not remunerable with a case fee, and an additional list of 71 negotiated extra remunerations. The German DRG system is subdi- vided into 23 major diagnosis categories (MDCs) which refer in principle to a body system or cause of a disease. The MDC category also defines the first of the four digits of a DRG. The second and third digits of a DRG indicate the respective partition. The partition differentiates between surgical procedures (o1-39), other procedures (40-59), and medical (conservative) procedures (60-99) carried out during a hospital stay, thus linking a DRG to benefits provided in a hospital. The fourth digit further subdivides a DRG according to a patient's clinical complexity level, which is comprised of such factors as complexity of secondary diagnoses, cause of discharge and patient gender [6].

For inpatient services not covered by the DRG system (e.g., new methods of treatment), agreements are made with the hospitals concerned. The local contractual partners inform the contract partners at the federal level of such agreements, who may then decide to initiate an evaluation process in order to exclude these new services from the benefit package [SGB V, Sect. 137c; V, Sect. 6 (2), Hospital Payment Act]. In principle however, as noted above, all health care services that are not explicitly excluded by a directive of the Federal Joint Committee can be provided at the expense of the SHI.

\section{Outpatient care}

The provision of medical and dental care must be regulated and secured by agreements between the respective regional physicians' association/regional dentists' association and the regional associations of the sickness funds (SGB V, Sect. 72). Whereas, in accordance with SGB V, Sect. $137 \mathrm{c}$, medical care in hospitals shall be, "adequate, expedient and cost-effective", for ambulatory care, in accordance with Sect. 135 , the criteria to be applied are "diagnostic and therapeutic expedience, medical necessity and cost-effectiveness." Thus the inclusion and/or exclusion of health care services from the benefit catalogues differ in the two sectors. In the outpatient sector a service provided must be confirmed to fulfill the criteria "expedience, necessity and cost-effectiveness" in order to be included into the catalogue of services and benefits. In contrast to that, health care 
Table2

Benefit-defining laws/ decrees and catalogues

Statutory Health SHI-general Insurance (SHI) - directives of general benefit the Federal regulation
SHI - special directives of the Federal Joint Commitee (positive)
SHI-appendices SHI- SHIto directives of the DRG EBM Federal Joint Commitee (negative)
SHI - SHI - Statutory long

BEMA BEL-II term care insur-

ance-general benefit regulation

Catalogue: type of document, actors and contents

\begin{tabular}{|c|c|c|c|c|c|c|c|}
\hline HC.1. & $x$ & $x$ & & $x(X)$ & $x$ & & \\
\hline HC.1.2 & $x$ & $\mathbf{x}$ & & $x(X)$ & $x$ & & \\
\hline HC.1.3.1 & $\mathrm{x}$ & $\mathbf{x}$ & & $x(X I)$ & $x$ & & \\
\hline HC.1.3.2 & $x$ & $x$ & $x(I)$ & X (XII) & & $\mathbf{x}$ & $x$ \\
\hline HC.1.3.3 & $x$ & $\mathrm{x}$ & X (II) & $x(X I)$ & $x$ & & \\
\hline HC.1.3.9 & $x$ & $x$ & X (III) & $x(X I)$ & & & \\
\hline HC.2.1/2.2 & $\mathbf{x}$ & & & & $\mathbf{x}$ & & \\
\hline HC.2.3 & $\mathbf{x}$ & & & & & & \\
\hline HC.3.1 & $x$ & & & & & & $x$ \\
\hline HC.3.2 & $x$ & & & & & & $x$ \\
\hline HC.3.3 & $x$ & & X (IV) & & & & $x$ \\
\hline HC.4.1 & $x$ & $\mathbf{x}$ & & & $\mathbf{x}$ & & \\
\hline HC.4.2 & $\mathbf{x}$ & $\mathbf{x}$ & & & $\mathrm{x}$ & $x$ & \\
\hline HC.4.3 & $x$ & & $x(V)$ & & & & \\
\hline HC.5.1.1 & $x$ & $\mathbf{x}$ & & & & & \\
\hline HC.5.1.2 & $x$ & $x$ & $x(V I)$ & & & & \\
\hline HC.5.2 & $x$ & $\mathbf{x}$ & x (VII) & & & & \\
\hline HC.6.1 & $x$ & $x$ & x (VIII) & & & & \\
\hline HC.6.3 & $x$ & & & & & & \\
\hline HC.6.4 & $x$ & $\mathbf{x}$ & x (IX) & & $x$ & $\mathbf{x}$ & \\
\hline HC.6.5 & $\mathbf{x}$ & & & & & & \\
\hline
\end{tabular}

FJC Federal Joint Committee, SHI Statutory Health Insurance, GBR General Benefit Regulation, DRG diagnosis-related group, EBM Uniform Value Scale, BEMA Uniform Value Scale-dentists, BEL-II Uniform Value Scale-dental technicians,

I Directives on the Provision of Prosthetic Services; II Directives on Psychotherapy; III Directives on Nonphysician Care; IV Directives on Home Nursing Care

V Directives on Patient Transport; VI Directives on OTC; VII Directives on Medical Aids; VIII Directives on Maternity Care

IX Directives on A. Early Detection of Cancer, B. Dental Prophylaxis \& C. Medical Examinations for the Early Detection of Diseases

X Appendix to Directive according to SGB V, Sect. 137c (to evaluate hospital procedures); XI Appendix to Directive on Medical Procedures,

XII Appendix to Directive on New Dental Procedures

services in the inpatient sector is excluded from the benefit catalogue of the sickness funds only if the criteria are proven to be unfulfilled. For this reason it is possible that the health care services provided in the inpatient sector are not included in the benefit catalogue of the outpatient sector [7].

\section{Basic medical and diagnostic care}

Insured persons are entitled to preventive care, detection, and treatment of diseases [SGB V, Sect. 28 (1)]. This entitlement also embraces complementary services by nonphysicians and practitioners, provided that they are prescribed by a physician. The legislative authority, however, does not define in detail the entitlements of the insured persons, but regulates the procedures with which the institutions of selfgovernance and the contractual partners determine the scope of SHI services [8].

In accordance with SGB V, Sect. 92 (1), the Federal Joint Committee issues directives in respect of adequate, expedient and cost-effective medical care for the insured persons. The directives consist of a general part that explains their aim, their users and mentions the correspond- ing paragraph in the SGB V. After the initial section the directives become more detailed. For example, the Directive on Medical Procedures that regulates the in- and exclusion of benefits in the outpatient sector initially defines the term of a new service and the conditions an evaluation is depended upon. Thereafter it is stated that the regional physicians' associations, the Federal Association of SHI Physicians and the federal associations of sickness funds have the right to propose services for their inclusion. Then the criteria for the inclusion of services, the classification of evidence and the decision-making process 

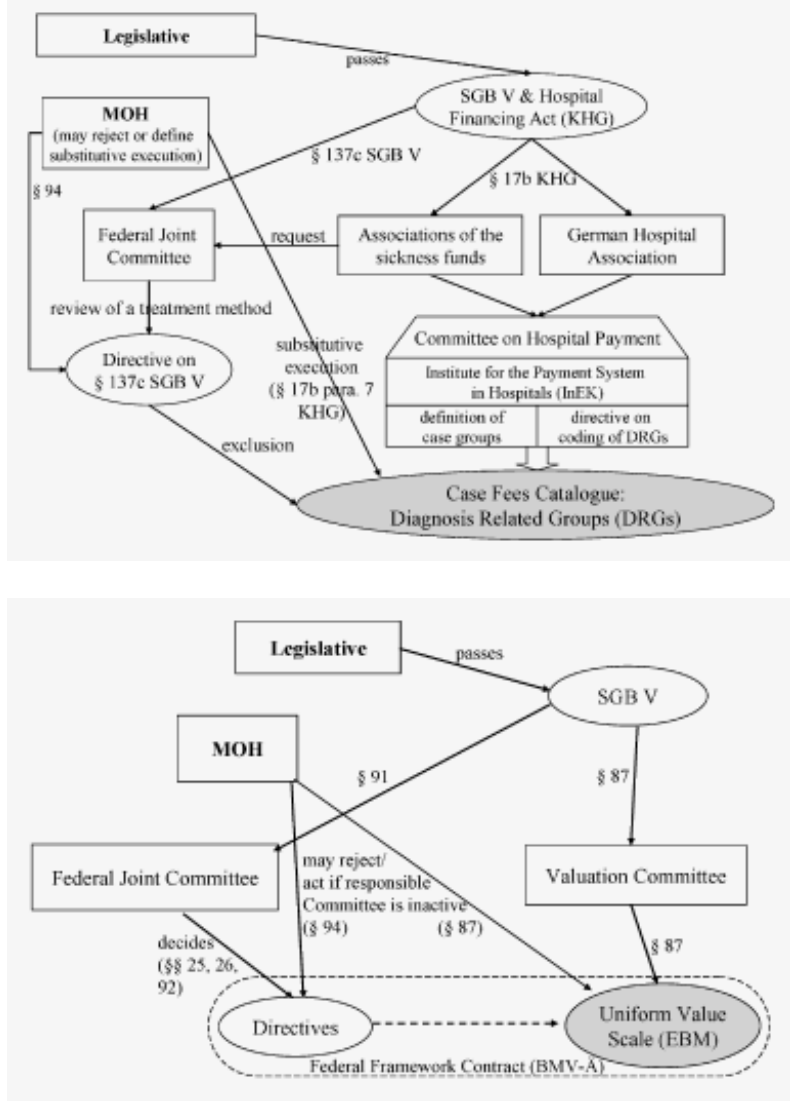

Fig. $1<$ DRG Case Fees Catalogue for inpatient care

Fig. $2<$ Uniform Value Scale for physicians for outpatient care are described in detail. The services included or excluded through the evaluation process are listed in the annexes [9].

While the Federal Joint Committee decides on the in- and exclusion of services into the benefit package, the Valuation Committee, which consists of seven representatives of the Federal Association of SHI Physicians and representatives of the federal associations of sickness funds, defines the actual benefit catalogue for the insured, the Uniform Value Scale (EBM). The EBM defines, as an integral component of the Federal Framework ContractPhysicians (BMV-Ä), the scope of medical care to be provided under the SHI throughout Germany. If the Valuation Committee fails to reach a consensus, at least two of its members or the Federal Ministry for Health and Social Security may demand that the extended Valuation Committee in accordance with SGB V, Sect. 87 (4), be brought in to resolve a split decision. Resolutions are to be submitted to the Ministry of Health, which, in the event of unresolved objection, may define alternative executions.

The BMV-Ä is concluded between the Federal Association of SHI Physicians and the federal associations of sickness funds (SGB V, Sect. 82). In addition to the scope of health care provided under the SHI, the $\mathrm{BMV}-\ddot{\mathrm{A}}$ regulates participation in ambulatory care, the pertinent aspects of quality assurance, and entitlement to benefits. Thus the EBM and the directives of the Federal Joint Committee are both integral parts of this contract. In Sect. 2 of the BMV-Ä, the description of a service in the EBM is stipulated as a condition for the provision of the respective service. As a result, the EBM constitutes the catalogue of services and benefits covered by the SHI (see $\bullet$ Fig. 2).

The broad structure and the contents of the EBM are stipulated in SGB V, Sect. 87 [10]: (a) The EBM displays the health care services covered by the SHI scheme and their monetary value in relation to one another in the form of a points system. (b) A basic remuneration for general practitioners is defined. (c) Health care services are grouped into packages of similar services. (d) Differentiation is made between the health care services to be provided exclusively by general practitioners and those to be provided exclusively by specialists. (e) The respective health care services are assigned exclusively to the groups of specialists that are allowed to provide them.

The EBM catalogue is structured into six main chapters and various sections. Chapter I describes general regulations regarding the provision and reimbursement of health care services. Chapters II-IV contain health care services related to different physician groups and/or special criteria. Chapter V lists the general health care services provided by most physicians reimbursed with case fees. Chapter VI contains appendices (e.g., a list of services which are already contained in other services and are therefore not reimbursed additionally) [11].

As an appendix to the BMV-Ä there is an agreement that applies to care provided by general practitioners under SGB V, Sect. 73. It defines the provision of medical treatments and the early detection of diseases. The definition of individual services to be provided is included in the EBM. In addition to these central agreements, which are uniform for all sickness funds, there are numerous "small" contracts determining the scope of the health care services covered by the German SHI scheme.

\section{Outpatient dental care}

While benefits for ambulatory physician services are legally defined in generic terms only, legislation regulating dental care is much more detailed in the SGB V. One reason for this is that the respective committee of the joint institutions until 2003 failed to provide more explicit definitions [12]. The basic entitlements of the insured to dental care are defined in SGB V, Sect. 28 (2): The insured are entitled to prevention, early detection, and treatment of diseases of the teeth, the mouth, and the jaw. Consequently only prophylactic treatment, basic dental care, and dental prosthetic services are covered by the sickness funds [13].

Similar to the definition of benefits for basic medical care, the directives of the Federal Joint Committee broadly define when patients are entitled to a benefit. However, they do not define specific items that must be included. Therefore the Dental Valuation Committee, which consists of representatives of the federal associations of the sickness funds and the Fed- 
eral Association of SHI Dentists defines the Uniform Value Scale for Dentists (BEMA; see - Fig. 3). The BEMA lists services that are reimbursed by the sickness funds, thereby explicitly defining the SHI benefit catalogue. The services of dental technicians producing the material needed for orthodontic or prosthetic services are listed in a similar framework, the Uniform Value Scale for Dental Technicians (BEL-II) which is negotiated by the same Committee.

Orthodontic treatments, except those for the treatment of abnormalities, are to begin during childhood and are excluded for insured parties over the age of 18 years (SGB V, Sect. 29). To prevent overprovision of services dentists must prepare a cost schedule that is reviewed by the sickness funds. Prosthetic services are only partially covered by the sickness funds and are therefore defined more explicitly. The insured receive a so-called "subsidy" as a percentage of a "standard" treatment, defined by the Federal Joint Committee in a directive according to SGB V, Sect. 56. The directive currently in force defines a standard treatment for 52 findings. For each standard treatment all reimbursable services of the dentists and the dental technicians are listed separately according to the BEMA and the BEL-II [14].

Sickness funds usually cover $50 \%$ of the standard treatment costs. This proportion can increase to $70 \%$ or $80 \%$ if a patient can prove yearly preventive dental checkups over the past 5 or 10 years, and the patient's efforts for dental hygiene are observable. Higher payment levels, up to full coverage of the costs of the standard treatment, are provided only for persons of very low income. Patients are free to choose nonstandard treatments [SGB V, Sect. 55 (5)] or include additional services [SGB V, Sect. 55 (4)]; however, the amount of sickness funds' payments remains unchanged.

\section{Outpatient care performed by nonphysicians}

The term "cures" subsumes health care services in Germany that are provided by nonmedical practitioners, which include professional, recognized therapists, such as physiotherapists and occupational therapists [15]. The entitlement of the insured

\section{Fig. 3 Uniform Value Scales for dentists and dental technicians}

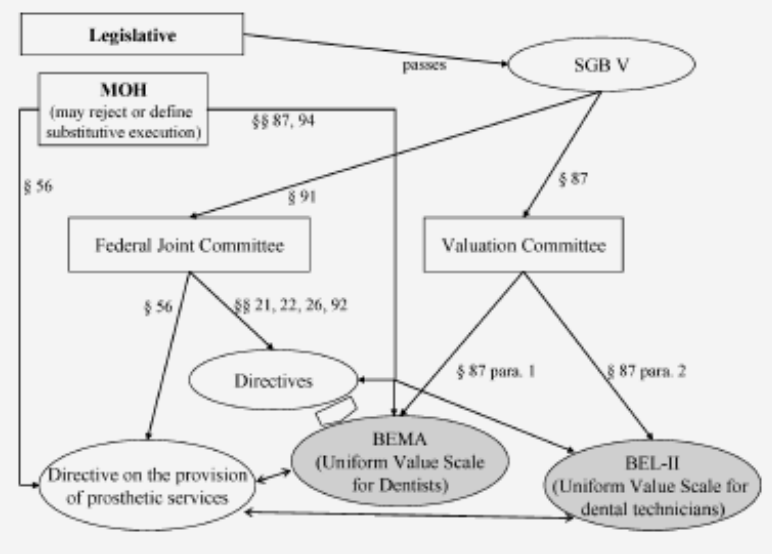

\section{Fig. 4 Catalogue of} Non-physician Care

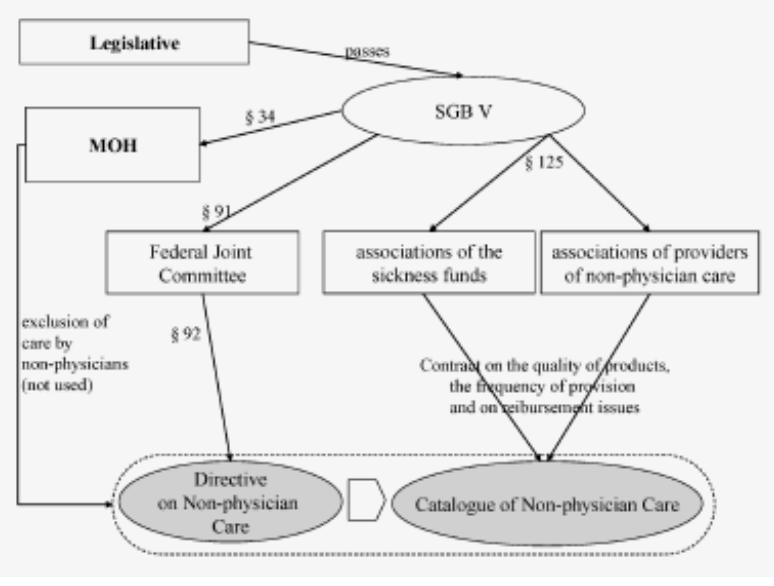

to cures is found in SGB V, Sect. 32. It is limited by copayments for insured parties over the age of 18 years under SGB V, Sect. 61 (3).

A further limitation on entitlements is imposed under SGB V, Sect. 34 (4), "Excluded Pharmaceuticals, Cures and Medical Aids." The Ministry of Health is entitled to exclude cures from the catalogue of services and benefits covered by the SHI through decrees, with the approval of the Federal Council (upper chamber of the federal Parliament). However, a corresponding legal decree does not exist at present.

The scope of services covered by the SHI scheme is explicitly described and regulated by the Directive on Non-physician Care issued by the Federal Joint Committee under SGB V, Sect. 92 [16]. The prescription of more cost-effective measures with equal efficacy, for example, drugs and other therapeutic appliances that achieve the same therapeutic objective, is to be given precedence. The benefits are listed in the directive in connection with an indication. New benefits and/or an extension of the indications for a given benefit may only be prescribed after the Federal Joint Committee has recognized their therapeutic value and included them into its directive (SGB V, Sect. 138).

The federal associations of sickness funds and representatives of non-physicians compile a Catalogue of Non-physician Care. The catalogue facilitates the implementation of the directive on Nonphysician Care issued by the Federal Joint Committee (see • Fig. 4; SGB V, Sect. 125), which regulates: (a) the content, scope and frequency of cures, (b) further training measures and quality assurance (c) the content and scope of collaboration between non-physicians and the prescribing SHI physician, (d) measures to meet the aim of cost-effectiveness, and (e) specifications for remuneration structures.

\section{Conclusions}

Despite the existence of various catalogues and directives for the SHI scheme, the benefit package is not defined in detail because the obligation of the cata- 
logues and their explicitness varies largely. Inpatient services not listed in the DRG catalogue can still be covered by the SHI scheme as long as they are not explicitly excluded by the Directive according to SGB V, Sect. 237c. However in the ambulatory sector only those procedures listed in the SHI EBM or in the SHI BEMA are covered as benefits in the outpatient sector.

With the exception of the Catalogue of Non-physician Care the benefits described in the DRG, EBM, BEMA, and BEL-II are the aggregate results of decisions taken at various levels, and they are not linked to specific indications. The reason for this is that they were originally defined for reimbursement and were not meant to define the SHI benefit basket in full detail. For example, as DRGs aggregate multiple procedures and diagnoses, benefits (medical procedures) provided under one DRG will vary from case to case. Additionally, the patient clinical complexity level of a DRG is determined by diagnoses including comorbidities, gender and cause of discharge and not on the basis of the actual services provided. Therefore the scope of a DRG is very broad. Conversely, the development of a DRG catalogue can also be seen as a starting point towards a more explicitly defined benefit catalogue, and subsequently lead to benefit catalogues where all approved interventions are listed and grouped around the relevant diagnoses [2].

In recent years strong efforts have been made by the German government to move towards a more explicitly defined benefit basket. The creation of the Federal Joint Committee out of four smaller committees for the different sectors of care can be considered an improvement. The number of issued directives since the inception of the committee supports the assumption that it is more productive than its predecessors. This development suggests that the German health care system is moving towards a more explicitly defined benefit catalogue [17].

Until now the use of cost-effectiveness studies as part of the decision criteria for the inclusion of new benefits is widely lacking. The criteria of cost-effectiveness was only taken into consideration for benefit decisions on medical devices. However, it is likely that it will be considered for oth- er benefits in the future as well. The creation of a supporting institute to the Federal Joint Committee, the Institute for Quality and Efficiency, in 2004, which increasingly commissions effectiveness studies, was one major step in that direction [2]. Although this will increase the information base for decisions $[18,19]$, the future impact of the cost-effectiveness criteria on the decision-making process and therefore on the structure of the health basket still remains unclear.

\section{Corresponding author Reinhard Busse}

Berlin University of Technology, Berlin, Germany e-mail: rbusse@tu-berlin.de

\section{Acknowledgements}

The results presented in this article are based on the project "Health Benefits and Service Costs in Europe-HealthBASKET" which is funded by the European Commission within the Sixth Framework Research Programme (grant no. SP21-CT2004-501588).

\section{References}

1. Busse R, Riesberg A (2004) Health care systems in transition: Deutschland. WHO Regional Office for Europe on behalf of the European Observatory on Health Systems and Policies, Copenhagen

2. Gibis B, Koch P, Bultman J (2004) Shifting criteria for benefit decisions. In: Saltman RB, Busse $R$, Figueras $J(e d)$ Social health insurance in western Europe. European Observatory on Health Care Systems, Copenhagen, pp 189-205

3. Organisation for Economic Cooperation and Development (2000) A system of health accounts. OECD: Paris

4. Busse R, Stargardt T, Schreyögg J, Simon C, Martin $M$ (2005) Defining benefit catalogues and entitlements to health care in Germany - decision makers, decision criteria and taxonomy of catalogues. Discussion paper 2005/5. Technical University Berlin, http://www.ww.tu-berlin.de/diskussionspapiere/2005/dp05-2005.pdf

5. Lungen M, Drege B, Rose A, Roebuck C, Plamper E, Lauterbach K (2004) Using diagnosis-related groups: the situation in the United Kingdom National Health Service and in Germany. Eur J Health Econ 5:287-289

6. Institute for the Remuneration of Hospitals (InEK) (2005) Coding directive G-DRG version 2005 http://www.g-drg.de/deutschesdrg/drg_kodier_ e.php?m=11

7. Niebuhr D, Rothgang H, Wasem J, Greß S (2004) Verfahren und Kriterien zur Bestimmung des Leistungskataloges in der gesetzlichen Krankenversicherung vor dem Hintergrund internationaler $\mathrm{Er}$ fahrungen. In: Niebuhr D, Rothgang H, Wasem J, Greß S (eds) Die Bestimmung des Leistungskataloges in der gesetzlichen Krankenversicherung, vol 2. Böckler Stiftung. pp 13-96
8. Kupsch S, Kern A, Klas C, Kressin B, Vienonen M, Beske $F(2000)$ Health service provision on a microcosmic level - an international comparison; results of a WHO/IGSF survey in 15 European countries. Institute for Health Systems Research, Kiel

9. Federal Joint Committee (2005) Directive for sufficient, appropriate and cost-effective dental prosthesis.http://www.g-ba.de/cms/upload/pdf/ richtlinien/RL-Zahnersatz-2005-12-08.pdf

10. Schauenburg B (2004) EBM 2000plus - die neue vertragsärztliche Gebührenordnung. BKK 92:241242

11. Federal Association of SHI Physicians (2005) Uniform Value Scale.http://www.kbv.de/ ebm2000plus/EBMGesamt.htm

12. Muschallik T, Ziermann K (2003) Zukunftsperspektiven der vertragszahnärztlichen Versorgung. Kassenzahnärztliche Bundesvereinigung, Cologne

13. Tiemann B, Klingenberger B, Weber M (2003) The system of dental care in Germany. Institut der Deutschen Zahnärzte, Cologne

14. Federal Joint Committee (2004) Directive on the provision of prosthetic services.http://www. g-ba.de/cms/upload/pdf/richtlinien/RL-Festzuschuss.pdf

15. Scharnetzky E, Deitermann B, Michel C, Glaeske G (2004) GEK - Heil- und Hilfsmittel. Report 2004. GEK Schriftenreihe zur Gesundheitsanalyse, vol 31. St Augustin: Asgard

16. Federal Joint Committee (2004) Directive on Care by non-physicians.http://www.g-ba.de/cms/upload/pdf/richtlinien/RL-Heilmittel-04-12-21.pdf

17. Schulenburg JM (2005) German health care system in transition: the difficult way to balance cost containment and solidarity. Eur J Health Econ 6:183-187

18. Ham C, Coulter A (2001) Explicit and implicit rationing: taking responsibility and avoiding blame for health care choices. J Health Serv Res Policy 6:163-169

19. Henke K-D, Schreyögg J (2004) Towards sustainable health care systems - strategies in health insurance schemes in France, Germany, Japan and The Netherlands. International Social Security Association: Geneva 